\title{
Análise da viabilidade econômico-financeira da cafeicultura: um estudo nas principais regiões produtoras de café do Brasil
}

Cássio Henrique Garcia Costa Mestrado em Administração na Universidade Federal de Lavras - UFLA Centro de Inteligência em Mercados, Campus UFLA. Lavras/MG. CEP: 37200-000

E-mail: cassionep@yahoo.com.br

Fabrício Teixeira Andrade Mestrado em Administração na Universidade Federal de Lavras - UFLA Centro de Inteligência em Mercados, Campus UFLA. Lavras/MG. CEP: 37200-000 E-mail: fabricioandrade84@yahoo.com.br

Luiz Gonzaga de Castro Júnior Mestre em Administração na Universidade Federal de Lavras - UFLA Centro de Inteligência em Mercados, Campus UFLA. Lavras/MG. CEP: 37200-000 E-mail: luiz.ufla@yahoo.com.br

\section{RESUMO}

O artigo objetiva analisar a viabilidade econômica da produção de café comparada à aplicação financeira com rendimento atrelado a taxa do Sistema Especial de Liquidação e Custodia (Selic) nos principais estados produtores do Brasil. A metodologia empregada na obtenção das informações e na estruturação das propriedades é a definida como painel que, essencialmente, é uma reunião realizada entre os pesquisadores e os técnicos e produtores locais. Os dados foram coletados nas seguintes cidades: Três Pontas, no estado de Minas Gerais, lúna no estado do Espírito Santo; Altinópolis, no estado de São Paulo; Ribeirão do Pinhal, no estado do Paraná; além de Vitória da Conquista, no estado da Bahia. Os critérios econômicos utilizados para avaliar a viabilidade dos projetos foram o Valor Presente Líquido (VPL) e a Taxa Interna de Retorno (TIR). Os resultados indicam que investir na cafeicultura é menos rentável na grande maioria dos casos se comparado aos investimentos equivalentes à taxa Selic.

Palavras-chave: Custos. Rentabilidade. Cafeicultura. Análise de Investimentos.

Analysis of economic and financial viability of coffee production: a study in the major coffee producing regions of Brazil 
Análise da viabilidade econômico-financeira da cafeicultura: um estudo nas principais regiões

produtoras de café do Brasil

Cássio Henrique Garcia Costa, Fabrício Teixeira Andrade, Luiz Gonzaga de Castro Júnior

\section{ABSTRACT}

This paper aims to analyze the economic viability of coffee production compared with the financial implementation rate of return tied to the Special Settlement and Custody (Selic) in the main producing states of Brazil. The methodology used in obtaining the information and the structuring of the properties is defined as the panel is essentially a meeting between the researchers and technicians and producers. Data were collected in the following cities: Three Points in the state of Minas Gerais, lúna the state of Espirito Santo; Altinópolis in the state of São Paulo, Ribeirão do Pinhal, Paraná state, in addition to Vitória, state of Bahia. The criteria used to evaluate the economic viability of the projects were the Net Present Value (NPV) and Internal Rate of Return (IRR). The results indicate that investing in coffee production is less profitable in most cases for investment equivalent to the Selic rate.

Key words: Costs. Profitability. Coffee Culture. Investment Analysis.

\section{INTRODUÇÃO}

O café está entre aqueles produtos brasileiros de maior destaque no mercado. Esta cultura é representativa para o saldo positivo da balança comercial brasileira e também para a geração de empregos, principalmente os diretos, os quais contribuem significativamente para a fixação do trabalhador no meio rural. Como no passado, o café continua sendo responsável pela abertura e consolidação de novas regiões agrícolas. Wedekin e Castro (1999) reiteram a importância dessa cultura afirmando que o café se constitui no produto mais representativo do Brasil no século XX, haja vista ter financiado mais de meio século de industrialização e desenvolvimento do país.

O Brasil é o maior produtor mundial de café (em 2008 produziu 2,7 milhões de toneladas) e o segundo maior consumidor, atrás apenas dos Estados Unidos. O consumo doméstico cresceu significativamente, entre 1990 e 2005, com aumento acumulado, nesse período, de 90\% (ABIC, 2009).

Devido à sua importância, a cafeicultura foi marcada por políticas protecionistas por parte do Estado, as quais visavam, principalmente, à sustentação do preço, o que estimulou a entrada de novos países produtores. Consequentemente, a cafeicultura brasileira reduziu sua participação relativa no mercado internacional. 
Análise da viabilidade econômico-financeira da cafeicultura: um estudo nas principais regiões produtoras de café do Brasil Cássio Henrique Garcia Costa, Fabrício Teixeira Andrade, Luiz Gonzaga de Castro Júnior

Segundo Matiello et al. (2005), na situação atual, de livre oferta e procura, com a expansão de novas regiões cafeeiras no mundo, é preciso levantar os problemas, técnicos e econômicos, que a lavoura cafeeira apresenta no Brasil e analisar os fatores favoráveis à competição. O setor produtivo deve se profissionalizar e tornar-se competitivo, visando à sustentabilidade em longo prazo.

A sustentabilidade é imprescindível para a cafeicultura atual e deve ser abordada integralmente para ser alcançada. Giordano (2003) corrobora essa premissa ao afirmar que sustentável tem como sinônimo a palavra suportável. Tem-se, portanto, que um determinado meio tem uma capacidade de sustentabilidade ou de suporte, determinada pelo conjunto de fatores que o compõe.

Em culturas perenes, como o café, o capital investido permanece imobilizado por um tempo relativamente longo. Por isso na avaliação do projeto é importante verificar no curto prazo, se as receitas auferidas em determinada safra são suficientes para cobrir os custos operacionais de produção. No longo prazo, é necessário verificar se as receitas oriundas do projeto são suficientes para cobrir os investimentos e continuar a custear a produção na amplitude de tempo considerada. Portanto, um projeto só é viável e, uma empresa só é sustentável, caso apresente rentabilidade. Vale ressaltar que essa rentabilidade deve ser superior às opções de investimento disponíveis no mercado, devido ao fato de a decisão de se investir na cafeicultura, geralmente, excluir alternativas de investimento.

Devido a esses e a vários outros fatores, para Matiello et al. (2005), a cafeicultura atual não pode, como no passado, ser estática, com o cafeicultor sendo avaliado somente pelo número de cafeeiros que possui em seu cadastro de Banco. Ela deve ser dinâmica, avaliada anualmente e ajustada de acordo com sua produtividade e rentabilidade, podendo ser ampliada ou reduzida conforme essas avaliações.

O presente trabalho tem o objetivo de comparar a rentabilidade da cafeicultura, representada por propriedades cafeeiras localizadas nas principais regiões produtoras do Brasil. O parâmetro utilizado na comparação é a taxa Selic. Para complementar esse objetivo, a cada uma das propriedades estudadas, atribuíram-se três cenários 
Análise da viabilidade econômico-financeira da cafeicultura: um estudo nas principais regiões produtoras de café do Brasil Cássio Henrique Garcia Costa, Fabrício Teixeira Andrade, Luiz Gonzaga de Castro Júnior

hipotéticos (otimista, conservador ou médio e pessimista), os quais foram submetidos isoladamente às mesmas análises.

Adicionalmente, avaliou-se o impacto dos gastos relativos à formação da lavoura, de modo que os resultados são apresentados primeiramente excluindo-se esses gastos e, posteriormente, incluindo-os. É importante destacar que, embora os cenários de avaliação sejam hipotéticos, a estruturação dos mesmos foi embasada em uma série histórica de dados de preços e de custos de produção, que foi formulada por meio de pesquisas mensais realizadas nas cidades pertencentes ao estudo.

Os resultados visam a embasar o processo decisório de se investir na cafeicultura no Brasil, o que, em épocas de altos preços do café, se configura como uma possibilidade atrativa. Desse modo, a decisão de transformar a poupança, muitas vezes acumulada durante décadas de trabalho em uma empresa produtora de café, pode ser mais acertada se forem analisadas alternativas e assim o resultado pode indicar a racionalidade econômica desta escolha.

Os dados foram coletados por meio de painéis em cidades localizadas nos principais estados produtores de café do Brasil, entre os meses de novembro de 2007 e dezembro de 2008.

O estudo está estruturado em cinco seções. Após a introdução se aborda a análise de projetos e os indicadores de viabilidade. A terceira seção descreve a metodologia utilizada. A quarta e a quinta seções trazem os resultados e discussões e as conclusões do trabalho, respectivamente.

\section{REFERENCIAL TEÓRICO}

Esta seção aborda o aspecto conceitual de análise de projetos, de gestão de riscos e as técnicas empregados no estudo para determinar a viabilidade econômicofinanceira da cafeicultura. 
Análise da viabilidade econômico-financeira da cafeicultura: um estudo nas principais regiões produtoras de café do Brasil Cássio Henrique Garcia Costa, Fabrício Teixeira Andrade, Luiz Gonzaga de Castro Júnior

\subsection{Análise de projeto}

As análises de projeto são imprescindíveis por fornecerem informações para as decisões necessárias nos diversos tipos de cenários que compõem o mercado. Essas decisões ocorrem frequentemente no dinâmico e competitivo ambiente dos negócios.

Segundo Woiler e Mathias (1996), os projetos podem ser classificados por tipo, de acordo com o setor onde estão inseridos. No caso de projetos macroeconômicos, eles podem ser agrícolas, industriais e de serviços. Em termos microeconômicos, eles podem ser classificados em: de implantação, expansão, modernização, relocalização e diversificação.

O mercado como se conhece hoje, devido a suas características estruturais, exige em contrapartida à rentabilidade alto grau de excelência das empresas, as quais terão suas expectativas frustradas caso deslizes estratégicos ocorram. Para evitar potenciais insolvências operacionais, as conjunturas, atual e futura de mercado, devem ser analisadas previamente a qualquer decisão, tanto no nível microeconômico como no macroeconômico, já que esses dois níveis são interdependentes.

Segundo Buarque (1991), a análise de projetos é feita pelas óticas econômica e privada, sendo a primeira entendida como a análise dos efeitos do projeto sobre a economia global na realização do bem coletivo. Já a análise privada considera a geração dos benefícios financeiros criados pelos projetos para a satisfação empresarial. Assim, a primeira análise apresenta os benefícios e custos do projeto em valores econômicos, e a segunda considera os valores em termos de mercado e permite avaliar a situação financeira da empresa ao longo do tempo.

Buarque (1991) salienta ainda que ambas são incompletas no estudo do mérito total dos projetos, pois nenhuma promove o estudo dos efeitos da distribuição dos benefícios e custos gerados sobre as diferentes classes sociais, o que evidencia a necessidade de uma avaliação social.

Uma decisão de investimento é a análise da relação entre os recursos demandados pela produção e a própria produção em si. Dessa forma, para que um investimento seja compensatório, é necessário que os benefícios gerados pela 
Análise da viabilidade econômico-financeira da cafeicultura: um estudo nas principais regiões produtoras de café do Brasil Cássio Henrique Garcia Costa, Fabrício Teixeira Andrade, Luiz Gonzaga de Castro Júnior

transformação dos recursos a montante em produtos destinados à troca, no procedimento de venda, sejam maiores que os custos inerentes ao processo produtivo.

Para Rezende e Oliveira (2001), os projetos são analisados pela ótica econômica, ou financeira, e social. Quando as receitas e custos são mensurados pelo valor privado, a avaliação será econômica ou financeira. Por sua vez, quando as receitas e os custos forem verificados pelo ponto de vista social, ter-se-á a análise social.

\subsection{Gestão de risco}

Segundo Gitman (2004), risco é a variabilidade associada à obtenção de retorno sobre algum investimento, ou seja, levando-se em consideração a possibilidade do retorno não existir, o risco é a probabilidade de haver retorno. De acordo com Corrêa (2005), no mercado agrícola o risco de mercado é o risco de perdas em função de flutuações adversas na cotação da commodity.

De acordo com Harwood et al. (1999) existem riscos adicionais à atividade do agronegócio, tais como: risco de produção, que pode ser apontado como um dos principais responsáveis pelas variações e quebras de safras devido à dificuldade em prever, na época do plantio, o que irá ocorrer durante o processo até a colheita, por variações das condições climáticas, ataques de pragas, queimadas, aplicação de novas tecnologias; e risco de preço, proveniente de alterações nos preços e nas relações de preços entre o momento em que a decisão é tomada e o período em que a venda da produção será realizada, sendo visto como barreira à produção e à alocação de recursos.

Markowitz (1952) afirma que existem basicamente dois tipos de risco: sistemático e não sistemático. O primeiro risco afeta a economia como um todo, de forma que não é possível eliminá-lo através de estratégias de diversificação, ao passo que o segundo afeta somente uma determinada empresa ou setor, e este sim pode ser reduzido a um valor aceitável, conforme a teoria de carteiras ou do portfólio. 
$\mathrm{Na}$ conjuntura da produção de café, o risco principal a ser observado é o risco não sistemático, ou específico, que afeta pontualmente o café e seu mercado. Esse risco pode ser mitigado, com uma gestão financeira e custos efetivos e com a estruturação de uma carteira de comercialização composta, em diferentes proporções, de alternativas de comercialização disponíveis.

Este trabalho se foca no risco não sistemático, tratando a gestão financeira como a base do processo de gestão de riscos das empresas que produzem café. A elaboração de cenários busca simular condições em que os componentes do risco não sistemático (produção e preço) variem, gerando impactos na capacidade de geração de resultados econômico-financeiros da cafeicultura.

\subsection{Indicadores de viabilidade}

Os indicadores de viabilidade são resultados de cálculos que indicam se um projeto é rentável e se investir nele é compensatório em relação a alternativas, sejam elas mutuamente excludentes ou não.

Quando o projeto transcorre por uma amplitude mais longa no tempo, faz-se necessário relacionar os valores futuros com valores presentes, o que é feito por meio de uma taxa de juros. Esse procedimento é importante devido ao fato de existir uma grande diferença em dispor de uma quantia hoje e após um período qualquer.

No que diz respeito à taxa de desconto, ela permite fazer comparações entre saldos financeiros presentes e futuros ao considerar o valor do dinheiro no tempo (LANNA, 2000). Para tal autor, em análise de projeto social a taxa deve ser igual à disposição da sociedade em deixar de consumir hoje para disponibilizar recursos para promover investimentos futuros. Já no caso da análise econômica privada, a taxa deve refletir o custo de oportunidade dos recursos empregados. Na análise financeira, a taxa é dada pelo mercado financeiro, ou seja, pela taxa de juros do mercado.

Dentre os critérios econômicos de viabilidade de projetos destacam-se o Valor Presente Líquido (VPL) e a Taxa Interna de Retorno (TIR). Segundo Contador (1981), os critérios são essenciais para aceitação e classificação da rentabilidade dos projetos. 
Análise da viabilidade econômico-financeira da cafeicultura: um estudo nas principais regiões produtoras de café do Brasil Cássio Henrique Garcia Costa, Fabrício Teixeira Andrade, Luiz Gonzaga de Castro Júnior

Entretanto, devem ser consideradas as especificidades de cada indicador, caso contrário, os resultados poderão se apresentar distorcidos.

Conceitualmente, o Valor Presente Líquido (VPL) é definido como o retorno monetário do investimento descontado o valor do dinheiro no tempo a uma taxa exógena, também definida como taxa de desconto. Assim o VPL é a soma do valor presente dos benefícios líquidos gerados pelo projeto. Nesse trabalho, a taxa utilizada é a Selic.

Por outro lado, a Taxa Interna de Retorno (TIR) representa a taxa de desconto endógena gerada pelo projeto que torna o VPL igual a zero, sendo definida como a taxa de juros composta oferecida pelo projeto.

Conforme Gitman (2004), o VPL é o critério de decisão preferível, não apresentando deficiências sérias; já a TIR é de fácil entendimento e transmissão, no entanto, apresenta deficiências, como: possibilidade de obtenção de respostas múltiplas e geração de decisões incorretas em projetos mutuamente excludentes.

\section{METODOLOGIA}

A pesquisa é de natureza descritiva e quantitativa. Segundo Andrade (2002), a pesquisa descritiva busca observar os fatos, registrá-los, analisá-los, classificá-los e interpreta-los, sem interferir neles. O processo de quantificação, na coleta e na interpretação das informações é feito para analisar a viabilidade da cafeicultura nos principais estados brasileiros produtores. Para isso, utilizaram-se dados existentes de custos de produção e preço de café em tais regiões.

\subsection{Origem e coleta de dados}

Os dados foram coletados nas seguintes cidades: Três Pontas, no estado de Minas Gerais, lúna no estado do Espírito Santo; Altinópolis, no estado de São Paulo; Ribeirão do Pinhal, no estado do Paraná; além de Vitória da Conquista, no estado da Bahia. 
Análise da viabilidade econômico-financeira da cafeicultura: um estudo nas principais regiões produtoras de café do Brasil Cássio Henrique Garcia Costa, Fabrício Teixeira Andrade, Luiz Gonzaga de Castro Júnior

A pesquisa para levantamento dos dados é uma iniciativa da Confederação Nacional da Agricultura e Pecuária (CNA), que financiou os pesquisadores e os demais recursos necessários para o trabalho. A escolha das localidades foi efetuada pela CNA, que seguiu uma ordenação decrescente, ou seja, foram escolhidas as cidades mais relevantes nos maiores estados produtores do Brasil.

A metodologia empregada na obtenção das informações e na estruturação das propriedades é a definida como painel que, essencialmente, é uma reunião realizada entre os pesquisadores e os técnicos e produtores locais (DE ZEN; PEREZ, 2002).

Com uma planilha previamente estruturada, porém não fixada, os pesquisadores conduziram as reuniões de modo que as informações não sofressem distorções devido a alguma convicção não unânime. É importante ressaltar a participação dos técnicos locais, o que contribuiu sobremaneira para 0 bom resultado dos painéis ao confirmarem, por meio de cálculos e do discernimento de cunho científico e prático, as informações resultantes das discussões. Os participantes deliberaram sobre o sistema de cultivo mais comum na região (moda) e procuraram expressar a propriedade integralmente.

No quadro abaixo constam os dados definidos durante a realização dos painéis relativos à área com lavoura de café em produção e a produtividade média.

Tabela 1: Produtividade (sacas/hectare) e área de lavoura de café (hectares).

\begin{tabular}{|c|c|c|}
\hline Cidades & Produtividade & Área com lavoura de café (ha) \\
\hline Três Pontas - MG & 27 & 30 \\
\hline Altinópolis - SP & 31 & 70 \\
\hline Ribeirão do Pinhal - PR & 36 & 51 \\
\hline lúna - ES & 27 & 6 \\
\hline Vitória da Conquista - BA & 30 & 40 \\
\hline
\end{tabular}

Fonte: dados da pesquisa (2009).

Foram alocados na planilha todos os itens de custo que estariam presentes em uma propriedade desse porte, desde o mais ínfimo gasto anual até o inventário 
Análise da viabilidade econômico-financeira da cafeicultura: um estudo nas principais regiões produtoras de café do Brasil Cássio Henrique Garcia Costa, Fabrício Teixeira Andrade, Luiz Gonzaga de Castro Júnior

completo. Todas as etapas do processo produtivo foram consideradas e os índices correspondentes validados em conjunto. Desse modo, elaborou-se, para cada região, uma estrutura de custos e despesas relativas a um ano, ou seja, que compreende um ciclo produtivo completo.

Os preços referentes aos dispêndios foram cotados posteriormente em estabelecimentos comerciais das cidades de origem dos dados e os parâmetros usados nos cálculos confirmados por meio de pesquisas realizadas em textos técnicos e por meio de entrevistas realizadas em organizações especializadas e na Universidade Federal de Lavras. Nessa última, entrevistaram-se professores do Departamento de Engenharia Agrícola e do Departamento de Agricultura. Essa verificação dos parâmetros conferiu maior credibilidade aos dados, visto que algumas inconsistências foram corrigidas.

Os itens identificados são referentes aos custos e às despesas; dentre esses, os desembolsos efetivos expressam a necessidade de caixa para custear a produção e se referem a: fertilizantes, defensivos, corretivos de solo, mão-de-obra permanente, mãode-obra eventual (incluindo mão-de-obra da colheita), encargos da mão-de-obra, assistência técnica, análises de solo e foliar, serviços contábeis, energia elétrica, juros de financiamentos de custeio e colheita, manutenção de máquinas, veículos, equipamentos e benfeitorias, tributos como o Imposto Territorial Rural (ITR) e o Imposto sobre a Propriedade de Veículos Automotores (IPVA), gastos com sindicato, despesas bancárias, combustíveis, gastos envolvendo a colheita, tais como rodos, rastelos, peneiras, luvas, botinas, sacarias, lonas, energia elétrica da colheita etc.

Utilizando-se como padrão a estrutura de custos e despesas elaborada na execução dos painéis, os itens correspondentes foram cotados mensalmente em cada cidade, dando origem a uma série de dados, a qual corresponde ao número de meses em que ocorreram as cotações. Esse procedimento originou, para cada cidade, vários valores de custos, os quais definem uma amplitude entre um custo máximo e um mínimo. Esses diferentes custos foram utilizados para se estruturarem os cenários de avaliação de viabilidade desse trabalho. 
Análise da viabilidade econômico-financeira da cafeicultura: um estudo nas principais regiões produtoras de café do Brasil Cássio Henrique Garcia Costa, Fabrício Teixeira Andrade, Luiz Gonzaga de Castro Júnior

$\mathrm{Na}$ composição das receitas, os preços de café recebidos pelos produtores de cada cidade foram cotados diariamente, de acordo com o tipo de café mais comercializado nas mesmas, e posteriormente, calculou-se a média mensal. Os preços médios foram multiplicados pela produção indicada nos painéis, originando-se a receita. Desse modo, de maneira equivalente ao efetuado com os custos, os diferentes valores de receita foram utilizados na estruturação dos cenários. Vale ressaltar que o valor cotado é o efetivamente recebido pelos produtores, isto é, já descontadas as taxas e impostos incidentes na comercialização.

\begin{tabular}{|l|l|l|}
\hline \multicolumn{1}{|c|}{ Cidade } & \multicolumn{1}{|c|}{ Tipo de Café } & \multicolumn{1}{c|}{ Período de cotação } \\
\hline Três Pontas - MG & Tipo 6 sul de Minas Gerais & Novembro 2007 a Dezembro 2008 \\
\hline Altinópolis - SP & Tipo 6 Mogiana São Paulo & Novembro 2007 a Dezembro 2008 \\
\hline Ribeirão do Pinhal - PR & Tipo 6-7 norte do Paraná & Novembro 2007 a Dezembro 2008 \\
\hline lúna - ES & Arábica Duro Vitória - ES & Janeiro 2008 a Dezembro 2008 \\
\hline Vitória da Conquista - BA & Tipo 6-7 Vitória da Conquista -BA & Maio 2008 a Dezembro 2008 \\
\hline
\end{tabular}

Quadro 1: Cidades e seus respectivos tipos de café utilizados no estudo e período de cotação de preços. Fonte: dados da pesquisa (2009).

\subsection{Saldos de caixa e fluxos de caixa}

Detectaram-se o tipo e a quantidade dos recursos necessários para a produção de café, bem como a quantidade produzida, de modo que se submetessem sem distorções à elaboração do fluxo de caixa. Posteriormente, as quantidades físicas (consumidas ou produzidas) foram multiplicadas pelas respectivas cotações mensais, gerando a quantidade de recurso monetário $(R \$)$ correspondente. Com esses dados, foram calculados os saldos de caixa anualizados de cada propriedade. O saldo de caixa é o resultado da diferença entre as entradas de caixa (nesse caso provenientes exclusivamente da venda do café produzido) e as saídas de caixa (desembolsos).

O fluxo de caixa projetado se inicia no ano de 2007, com o investimento em benfeitorias, máquinas e equipamentos. Para os anos posteriores os saldos de caixa foram mantidos uniformes, tendo como base o ano de 2008.

Uma questão relevante nesse estudo é a escolha da amplitude de tempo considerada. Segundo Woiler e Mathias (1996), a problemática da determinação da 
Análise da viabilidade econômico-financeira da cafeicultura: um estudo nas principais regiões produtoras de café do Brasil Cássio Henrique Garcia Costa, Fabrício Teixeira Andrade, Luiz Gonzaga de Castro Júnior

duração do projeto se deve ao fato de períodos longos diminuírem a confiabilidade dos resultados e períodos curtos subestimarem retornos ao omitirem fluxos de caixa futuros. Para se solucionar esse problema, foi utilizada uma das indicações do mesmo autor e se considerou o horizonte temporal correspondente à expectativa de vida útil dos ativos imobilizados. Os valores correspondentes ao ano de 2007 dizem respeito ao investimento inicial nas propriedades (benfeitorias, máquinas e implementos). De 2008 a 2026 são considerados os saldos de caixa da propriedade; em 2027 os valores residuais dos ativos não totalmente depreciados foram acrescidos ao saldo de caixa. No caso da cidade de lúna - ES, os saldos de caixa se mantiveram constantes até o ultimo ano, visto que seus ativos correspondentes ao investimento inicial foram totalmente depreciados durante o período do projeto.

Ao longo da vida útil do projeto, Noronha (1987) destaca que o conjunto de preços das variáveis do fluxo de caixa pode ser originado de duas maneiras. A primeira pela previsão futura dos preços, e a segunda pela repetição dos preços coletados na época da elaboração do projeto ao longo de sua vida útil, tendo como hipótese que, ao longo do tempo os preços relativos e o nível geral de preços sejam constantes. Devido à dificuldade e imprecisão de uma estimativa de preços para um prazo tão longo, nos anos subsequentes foram mantidas as estimativas de 2008. Portanto, os valores não foram corrigidos (inflacionados ou deflacionados), o que possibilita verificar, se mantidas as condições de custos e volume produzido, a cafeicultura é mais ou menos rentável em relação taxa básica de juros (Selic).

Os gastos destinados à implantação das lavouras de café, por serem também investimentos, devem compor a saída de caixa do primeiro ano do projeto. Entretanto, como existem lavouras de café já implantadas nas cidades participantes desse estudo (algumas há muitos anos), optou-se por analisar a viabilidade dos casos estudados excluindo-se esses gastos. Portanto, os resultados são apresentados de modo que se possam verificar ambas as situações, ou seja, uma excluindo-se os gastos relativos à implantação das lavouras e outra os incluindo. 
Análise da viabilidade econômico-financeira da cafeicultura: um estudo nas principais regiões produtoras de café do Brasil Cássio Henrique Garcia Costa, Fabrício Teixeira Andrade, Luiz Gonzaga de Castro Júnior

\subsection{Elaboração de cenários}

A elaboração de diferentes cenários objetivou tornar a análise mais completa, visto que a cafeicultura está inserida em um ambiente caracterizado por alta volatilidade, tanto de custos de produção como de preços de venda do café. Portanto, os resultados oriundos de cenários diferentes propiciam uma visão mais ampla e real, o que possibilita avaliar a viabilidade em situações distintas, porém prováveis. Essas situações são prováveis devido ao fato de serem estimadas por meio de dados coletados nas regiões estudadas.

A série de dados utilizada na elaboração dos cenários possui a seguinte amplitude temporal: entre os meses de novembro de 2007 e dezembro de 2008.

Mantendo-se constante a estrutura de custos e de receita, foram elaborados três fluxos de caixa para cada propriedade, quais sejam:

1) Cenário "otimista" - valores máximos de entrada de caixa (maiores preços de café) e os mínimos de saída de caixa (menores desembolsos);

2) Cenário "conservador" - entradas e saídas de caixa médios;

3) Cenário "pessimista" - valores mínimos de entrada de caixa (menores preços de café) e os máximos de saída de caixa (maiores desembolsos).

Por meio do quadro a seguir, podem ser visualizados os dados utilizados na estruturação dos diferentes cenários para todas as cidades estudadas. Os valores de saídas de caixa são relativos aos desembolsos efetivos anuais. 
Análise da viabilidade econômico-financeira da cafeicultura: um estudo nas principais regiões produtoras de café do Brasil

Cássio Henrique Garcia Costa, Fabrício Teixeira Andrade, Luiz Gonzaga de Castro Júnior

Tabela 2: Preço de café (Reais/saca de 60kg), saídas de caixa (Reais total) e saídas de caixa (Reais por unidade de área produtiva, em hectares) para os três cenários

\begin{tabular}{|c|l|r|r|r|}
\hline CIDADE & CENÁRIO & PREÇO CAFÉ & SAÍDAS DE CAIXA & SAÍDAS DE CAIXA/ha \\
\hline \multirow{3}{*}{ TRÊS PONTAS-MG } & Otimista & 281,21 & $184.696,50$ & $6.156,55$ \\
\cline { 2 - 5 } & Conservador & 257,95 & $203.226,90$ & $6.774,23$ \\
\cline { 2 - 5 } & Pessimista & 245,10 & $215.190,00$ & $7.173,00$ \\
\hline \multirow{3}{*}{ ALTINÓPOLIS-SP } & Otimista & 280,58 & $416.778,60$ & $5.953,98$ \\
\cline { 2 - 5 } & Conservador & 257,91 & $470.915,90$ & $6.727,37$ \\
\cline { 2 - 5 } & Pessimista & 243,80 & $503.759,90$ & $7.196,57$ \\
\hline \multirow{3}{*}{ RIBEIRÃO DO PINHAL-PR } & Otimista & 267,16 & $390.255,06$ & $7.652,06$ \\
\cline { 2 - 5 } & Conservador & 243,32 & $437.162,31$ & $8.571,81$ \\
\cline { 2 - 5 } & Pessimista & 231,45 & $474.656,49$ & $9.306,99$ \\
\hline \multirow{3}{*}{ IÚNA - ES } & Otimista & 265,32 & $17.027,70$ & $2.837,95$ \\
\cline { 2 - 5 } & Conservador & 244,25 & $21.062,52$ & $3.510,42$ \\
\cline { 2 - 5 } & Pessimista & 232,86 & $23.861,58$ & \\
\hline \multirow{2}{*}{ VITÓRIA DA CONQUISTA-BA } & 243,41 & $281.894,47$ & \\
& Otimista & 235,15 & $328.122,95$ & \\
\cline { 2 - 5 } & Conservador & 226,50 & $338.271,69$ & \\
\cline { 2 - 5 } & Pessimista & & & $8.047,36$ \\
\hline
\end{tabular}

Fonte: dados da pesquisa (2009).

\section{RESULTADOS E DISCUSSÕES}

$\mathrm{Na}$ Tabela 3 são apresentados os fluxos de caixa simplificados dos cenários OTIMISTA, CONSERVADOR e PESSIMISTA para as cinco cidades que compõem o estudo. Primeiramente são apresentados os fluxos de caixa excluindo-se os gastos com implantação de lavouras (SITUAÇÃO 1) e, posteriormente, incluindo-os (SITUAÇÃO 2).

SITUAÇÃO 1 - sem os gastos com implantação de lavoura (subseção 4.1) 
Análise da viabilidade econômico-financeira da cafeicultura: um estudo nas principais regiões produtoras de café do Brasil

Cássio Henrique Garcia Costa, Fabrício Teixeira Andrade, Luiz Gonzaga de Castro Júnior

Tabela 3: Fluxos de caixa simplificados anuais para os três cenários

\begin{tabular}{|c|c|c|c|c|}
\hline \multirow{2}{*}{ CIDADE } & \multirow{2}{*}{ CENÁRIO } & \multicolumn{3}{|c|}{ FLUXOS DE CAIXA } \\
\hline & & 2007 & 2008 a 2026 & 2027 \\
\hline \multirow{3}{*}{ TRÊS PONTAS-MG } & Otimista & $-243.651,78$ & $43.083,60$ & $65.217,60$ \\
\hline & Conservador & $-245.702,93$ & $5.711,14$ & $27.845,14$ \\
\hline & Pessimista & $-250.479,45$ & $16.659,00$ & $5.475,00$ \\
\hline \multirow{3}{*}{ ALTINÓPOLIS-SP } & Otimista & $-534.520,00$ & $192.080,00$ & $255.254,00$ \\
\hline & Conservador & $-538.618,82$ & $88.751,75$ & $151.925,75$ \\
\hline & Pessimista & $-552.163,26$ & $25.286,10$ & $88.460,10$ \\
\hline \multirow{3}{*}{ RIBEIRÃO DO PINHAL-PR } & Otimista & $-701.980,00$ & $100.250,70$ & $142.250,70$ \\
\hline & Conservador & - 707.724,41 & $9.578,08$ & $51.578,08$ \\
\hline & Pessimista & - 742.788,96 & $49.714,29$ & $7.714,29$ \\
\hline \multirow{3}{*}{ IÚNA - ES } & Otimista & $-\quad 85.215,00$ & $8.761,40$ & $8.761,40$ \\
\hline & Conservador & $-87.015,06$ & $2.678,76$ & $2.678,76$ \\
\hline & Pessimista & $-\quad 85.876,00$ & $1.227,59$ & $1.227,59$ \\
\hline \multirow{3}{*}{ VITÓRIA DA CONQUISTA-BA } & Otimista & $-467.780,00$ & $10.197,53$ & $125.511,53$ \\
\hline & Conservador & $-470.727,74$ & $45.938,45$ & $70.259,87$ \\
\hline & Pessimista & - 478.748,57 & $66.471,69$ & $52.132,88$ \\
\hline
\end{tabular}

Fonte: dados da pesquisa (2009).

SITUAÇÃO 2 - com os gastos de implantação de lavouras (subseção 4.1)

Tabela 4: Fluxos de caixa simplificados anuais para os três cenários

\begin{tabular}{|c|c|c|c|c|}
\hline \multirow{2}{*}{ CIDADE } & \multirow{2}{*}{ CENÁRIO } & \multicolumn{3}{|c|}{ FLUXOS DE CAIXA } \\
\hline & & 2007 & 2008 a 2026 & 2027 \\
\hline \multirow{3}{*}{ TRÊS PONTAS-MG } & Otimista & $468.651,78$ & $43.083,60$ & $65.217,60$ \\
\hline & \begin{tabular}{|l|} 
Conservador \\
\end{tabular} & $470.703,00$ & $5.711,00$ & $27.845,00$ \\
\hline & Pessimista & $475.479,45$ & $16.659,00$ & $5.475,00$ \\
\hline \multirow{3}{*}{ ALTINÓPOLIS-SP } & Otimista & $1.059 .520,00$ & $192.080,00$ & $255.254,00$ \\
\hline & \begin{tabular}{|l|} 
Conservador \\
\end{tabular} & $1.063 .618,82$ & $88.751,75$ & $151.925,75$ \\
\hline & Pessimista & $1.077 .163,00$ & $25.286,00$ & $88.460,00$ \\
\hline \multirow{3}{*}{ RIBEIRÃO DO PINHAL-PR } & Otimista & $1.084 .480,00$ & $100.251,00$ & $142.251,00$ \\
\hline & \begin{tabular}{|l|} 
Conservador \\
\end{tabular} & $1.090 .224,00$ & $9.578,00$ & $51.578,00$ \\
\hline & Pessimista & $1.125 .289,00$ & $49.714,00$ & $7.714,00$ \\
\hline \multirow{3}{*}{ IÚNA - ES } & Otimista & $130.215,00$ & $8.761,00$ & $8.761,00$ \\
\hline & Conservador & $132.015,00$ & $2.679,00$ & $2.679,00$ \\
\hline & Pessimista & $130.877,00$ & $1.228,00$ & $1.228,00$ \\
\hline \multirow{3}{*}{ VITÓRIA DA CONQUISTA-BA } & Otimista & $767.780,00$ & $10.198,00$ & $125.512,00$ \\
\hline & \begin{tabular}{|l|} 
Conservador \\
\end{tabular} & $770.728,00$ & $45.938,00$ & $70.260,00$ \\
\hline & Pessimista & $778.749,00$ & $66.472,00$ & $52.133,00$ \\
\hline
\end{tabular}

Fonte: dados da pesquisa (2009). 
Análise da viabilidade econômico-financeira da cafeicultura: um estudo nas principais regiões produtoras de café do Brasil Cássio Henrique Garcia Costa, Fabrício Teixeira Andrade, Luiz Gonzaga de Castro Júnior

Os indicadores VPL e TIR são apresentados para os três cenários em duas situações, quais sejam: SITUAÇÃO 1 - excluindo-se os gastos necessários para a implantação de lavouras e, SITUAÇÃO 2 - incluindo-se esses gastos no fluxo de caixa.

\subsection{SITUAÇÃO 1 - excluindo-se os gastos com implantação de lavoura}

Em Três Pontas - MG o VPL apresenta valor de -R $\$ 370.219,52$ no cenário pessimista, passando a $-\mathrm{R} \$ 201.747,79$ no cenário conservador e para $R \$ 73.779,20$ no cenário otimista. Portanto, a cafeicultura se mostra uma atividade viável frente à taxa Selic somente no cenário otimista, uma vez que nesse cenário o VPL é maior que zero. Isso indica que tendo como taxa de desconto 12,33\% apenas nesse cenário a cafeicultura agrega valor ao investimento.

A Taxa Interna de Retorno (TIR) foi de $16,98 \%$ no cenário otimista; já nos outros dois casos, mesmo a uma taxa de desconto nula o VPL ainda é negativo, portanto não apresentam TIR.

Tabela 5: VPL e TIR nos três cenários para Três Pontas - MG

\begin{tabular}{|l|c|c|c|}
\hline \multirow{2}{*}{\multicolumn{1}{|c|}{ Indicadores }} & \multicolumn{3}{|c|}{ Cenários } \\
\cline { 2 - 4 } & Pessimista & Conservador & Otimista \\
\hline Taxa interna de Retorno (\%) & - & - & $16,98 \%$ \\
\hline Rendimento Selic (\%) & $12,33 \%$ & $12,33 \%$ & $12,33 \%$ \\
\hline Valor Presente Líquido (R\$) & $-\mathrm{R} \$ 370.219,52$ & $-\mathrm{R} \$ 201.747,79$ & $\mathrm{R} \$ 73.779,20$ \\
\hline
\end{tabular}

Fonte: dados da pesquisa (2009).

Em Altinópolis - SP, os VPL resultantes são - $\mathrm{R} \$ 359.433,02$ no cenário pessimista, $R \$ 117.003,73$ no cenário conservador e $R \$ 893.250,77$ no cenário otimista.

A TIR obtida nos três cenários é $0,62 \%, 15,58 \%$ e $35,88 \%$, respectivamente, nos cenários pessimista, conservador e otimista. Portanto, os resultados indicados pela TIR corroboram os obtidos por meio do VPL, visto que uma TIR menor do que a taxa de desconto (cenário pessimista) gera um VPL negativo. 
Análise da viabilidade econômico-financeira da cafeicultura: um estudo nas principais regiões produtoras de café do Brasil Cássio Henrique Garcia Costa, Fabrício Teixeira Andrade, Luiz Gonzaga de Castro Júnior

Nessas condições a cafeicultura se mostra mais rentável que a taxa Selic a partir do ponto em que ocorre qualquer combinação de preços de café médios ou acima da média, com desembolsos médios ou menores do que a média encontrada na série de dados.

Tabela 6: VPL e TIR nos três cenários para Altinópolis - SP

\begin{tabular}{|l|c|c|c|}
\hline \multirow{2}{*}{\multicolumn{1}{|c|}{ Indicadores }} & \multicolumn{3}{c|}{ Cenários } \\
\cline { 2 - 4 } & Pessimista & Conservador & Otimista \\
\hline Taxa interna de Retorno (\%) & $0,62 \%$ & $15,68 \%$ & $35,88 \%$ \\
\hline Rendimento Selic (\%) & $12,33 \%$ & $12,33 \%$ & $12,33 \%$ \\
\hline Valor Presente Líquido (R\$) & $-\mathrm{R} \$ 359.433,02$ & $\mathrm{R} \$ 117.003,73$ & $\mathrm{R} \$ 893.250,77$ \\
\hline
\end{tabular}

Fonte: dados da pesquisa (2009).

Em Ribeirão do Pinhal - PR, a cafeicultura é inviável em comparação à taxa Selic nos cenários pessimista e conservador, com valores de VPL de -R $\$ 1.102 .471,89$ e - $R \$ 633.530,87$ respectivamente. No cenário otimista, que apresenta VPL de $R \$$ $35.717,37$ a cafeicultura se mostra mais rentável que a taxa de $12,33 \%$ (Selic). A TIR indica o mesmo resultado, uma vez que se mostra superior à taxa de desconto apenas no cenário otimista, $13,14 \%$.

Tabela 7: VPL e TIR nos três cenários para Ribeirão do Pinhal - PR

\begin{tabular}{|l|c|c|c|}
\hline \multirow{2}{*}{\multicolumn{1}{|c|}{ Indicadores }} & \multicolumn{3}{|c|}{ Cenários } \\
\cline { 2 - 4 } & Pessimista & Conservador & Otimista \\
\hline Taxa interna de Retorno (\%) & - & - & $13,14 \%$ \\
\hline Rendimento Selic (\%) & $12,33 \%$ & $12,33 \%$ & $12,33 \%$ \\
\hline Valor Presente Líquido (R\$) & $-\mathrm{R} \$ 1.102 .471,89$ & $-\mathrm{R} \$ 633.530,87$ & $\mathrm{R} \$ 35.717,37$ \\
\hline
\end{tabular}

Fonte: dados da pesquisa (2009).

Em lúna - ES, a cafeicultura se mostra inviável frente à Selic em todos os cenários, uma vez que não apresenta VPL superior a zero e TIR maior que 12,33\% (Selic) em nenhum deles. Como pode ser observado na Tabela 8 , no cenário otimista a TIR é de $8,13 \%$, valor menor que a taxa de desconto, o que confirma o VPL negativo. 
Análise da viabilidade econômico-financeira da cafeicultura: um estudo nas principais regiões produtoras de café do Brasil Cássio Henrique Garcia Costa, Fabrício Teixeira Andrade, Luiz Gonzaga de Castro Júnior

Tabela 8: VPL e TIR nos três cenários para lúna - ES

\begin{tabular}{|l|c|c|c|}
\hline \multirow{2}{*}{\multicolumn{1}{|c|}{ Indicadores }} & \multicolumn{3}{c|}{ Cenários } \\
\cline { 2 - 4 } & Pessimista & Conservador & Otimista \\
\hline Taxa interna de Retorno (\%) & - & - & $8,13 \%$ \\
\hline Rendimento Selic (\%) & $12,33 \%$ & $12,33 \%$ & $12,33 \%$ \\
\hline Valor Presente Líquido (R\$) & $-\mathrm{R} \$ 94.858,97$ & $-\mathrm{R} \$ 67.413,02$ & $-\mathrm{R} \$ 21.102,76$ \\
\hline
\end{tabular}

Fonte: dados da pesquisa (2009).

Em Vitória da Conquista - BA, a cafeicultura é inviável frente à Selic em todos os cenários. Isso é evidenciado por ambos os indicadores, já que o VPL é negativo e a TIR inexistente.

Tabela 9: VPL e TIR nos três cenários para Vitória da Conquista - BA

\begin{tabular}{|l|c|c|c|}
\hline \multirow{2}{*}{ Indicadores } & \multicolumn{3}{c|}{ Cenários } \\
\cline { 2 - 4 } & Pessimista & Conservador & Otimista \\
\hline Taxa interna de Retorno (\%) & - & - & - \\
\hline Rendimento Selic (\%) & $12,33 \%$ & $12,33 \%$ & $12,33 \%$ \\
\hline Valor Presente Líquido (R\$) & $-\mathrm{R} \$ 953.567,51$ & $-\mathrm{R} \$ 795.528,31$ & $-\mathrm{R} \$ 381.887,68$ \\
\hline
\end{tabular}

Fonte: dados da pesquisa (2009).

\subsection{SITUAÇÃO 2 - incluindo-se os gastos com implantação de lavouras}

Em Três Pontas, o VPL apresenta valores negativos nos três cenários analisados quando considerado o investimento em formação de lavoura. O VPL passa de -R $\$$ $595.219,52$ no cenário pessimista, para - $R \$ 456.747,79$ no cenário conservador e para R\$ 151.220,80 no cenário otimista. Esses resultados demonstram que quando comparada à taxa Selic a cafeicultura é inviável nos três cenários analisados. Portanto, quaisquer que sejam as condições de desembolsos e valores de venda do café, a atividade cafeeira terá rentabilidade insatisfatória quando comparada a taxa de 12,33\% (Selic). Somente o cenário otimista apresentou TIR. 
Análise da viabilidade econômico-financeira da cafeicultura: um estudo nas principais regiões produtoras de café do Brasil Cássio Henrique Garcia Costa, Fabrício Teixeira Andrade, Luiz Gonzaga de Castro Júnior

Tabela 10: VPL e TIR nos três cenários para Três Pontas - MG

\begin{tabular}{|l|c|c|c|}
\hline \multirow{2}{*}{\multicolumn{1}{|c|}{ Indicadores }} & \multicolumn{3}{c|}{ Cenários } \\
\cline { 2 - 4 } & Pessimista & Conservador & Otimista \\
\hline Taxa interna de Retorno (\%) & - & - & $6,82 \%$ \\
\hline Rendimento Selic (\%) & $12,33 \%$ & $12,33 \%$ & $12,33 \%$ \\
\hline Valor Presente Líquido (R\$) & $-\mathrm{R} \$ 595.219,52$ & $-\mathrm{R} \$ 426.747,79$ & $-\mathrm{R} \$ 151.220,80$ \\
\hline
\end{tabular}

Fonte: dados da pesquisa (2009).

Em Altinópolis - SP, o VPL é -R $\$ 884.433,02$ no cenário pessimista, - $R \$$ 407.996,27 no cenário conservador e chega aos $\mathrm{R} \$ 352.214,91$ no cenário otimista. Portanto, a cafeicultura se mostra viável frente à Selic apenas no cenário otimista. Isso é confirmado pelos dois indicadores, visto que a TIR é maior que 12,33\% e o VPL é positivo apenas nesse cenário.

Tabela 11: VPL e TIR nos três cenários para Altinópolis - SP

\begin{tabular}{|l|c|c|c|}
\hline \multirow{2}{*}{ Indicadores } & \multicolumn{3}{c|}{ Cenários } \\
\cline { 2 - 4 } & Pessimista & Conservador & Otimista \\
\hline Taxa interna de Retorno (\%) & - & $5,71 \%$ & $17,44 \%$ \\
\hline Rendimento Selic (\%) & $12,33 \%$ & $12,33 \%$ & $12,33 \%$ \\
\hline Valor Presente Líquido (R\$) & $-\mathrm{R} \$ 884.433,02$ & $-\mathrm{R} \$ 407.996,27$ & $\mathrm{R} \$ 352.214,91$ \\
\hline
\end{tabular}

Fonte: dados da pesquisa (2009).

Em Ribeirão do Pinhal - PR o VPL é -R\$ 1.484.917,89 no cenário pessimista, $\mathrm{R} \$ 1.016 .030,87$ no cenário conservador e $-\mathrm{R} \$ 346.782,63$ no otimista. Logo, a cafeicultura não se mostra mais rentável que a taxa Selic em nenhum dos cenários avaliados. A única TIR obtida para essa condição é de $6,86 \%$ no cenário otimista, mas ainda assim é menor que a Selic. 
Análise da viabilidade econômico-financeira da cafeicultura: um estudo nas principais regiões produtoras de café do Brasil

Cássio Henrique Garcia Costa, Fabrício Teixeira Andrade, Luiz Gonzaga de Castro Júnior

Tabela 12: VPL e TIR nos três cenários para Ribeirão do Pinhal - PR

\begin{tabular}{|l|c|c|c|}
\hline \multirow{2}{*}{\multicolumn{1}{|c|}{ Indicadores }} & \multicolumn{3}{|c|}{ Cenários } \\
\cline { 2 - 4 } & Pessimista & Conservador & Otimista \\
\hline Taxa interna de Retorno (\%) & - & - & $6,86 \%$ \\
\hline Rendimento Selic (\%) & $12,33 \%$ & $12,33 \%$ & $12,33 \%$ \\
\hline Valor Presente Líquido (R\$) & $-\mathrm{R} \$ 1.484 .971,89$ & $-\mathrm{R} \$ 1.016 .030,87$ & $-\mathrm{R} \$ 346.782,63$ \\
\hline
\end{tabular}

Fonte: dados da pesquisa (2009).

Em lúna - ES, o VPL é -R\$139.859,87 no cenário pessimista, -R\$ 112.413,02 no conservador e $-\mathrm{R} \$ 66.102,76$ no otimista. Portanto a cafeicultura não se mostra mais rentável que a taxa Selic em nenhum dos cenários observados. A TIR calculada para 0 cenário otimista é 3,01\%, valor inferior à taxa Selic.

Tabela 13: VPL e TIR nos três cenários para lúna -ES

\begin{tabular}{|l|c|c|c|}
\hline \multirow{2}{*}{\multicolumn{1}{|c|}{ Indicadores }} & \multicolumn{3}{c|}{ Cenários } \\
\cline { 2 - 4 } & Pessimista & Conservador & Otimista \\
\hline Taxa interna de Retorno (\%) & - & - & $3,01 \%$ \\
\hline Rendimento Selic (\%) & $12,33 \%$ & $12,33 \%$ & $12,33 \%$ \\
\hline Valor Presente Líquido (R\$) & $-\mathrm{R} \$ 139.859,87$ & $-\mathrm{R} \$ 112.413,02$ & $-\mathrm{R} \$ 66.102,76$ \\
\hline
\end{tabular}

Fonte: dados da pesquisa (2009).

Em Vitória da Conquista - BA, o VPL é -R\$1.253.567,51no cenário pessimista, $-R \$ 1.095 .528,31$ no cenário conservador e - $R \$ 681.887,68$ no cenário otimista. A TIR não apresenta valor positivo em nenhum dos cenários.

Tabela 14: VPL e TIR nos três cenários para Vitória da Conquista - BA

\begin{tabular}{|l|c|c|c|}
\hline \multirow{2}{*}{\multicolumn{1}{|c|}{ Indicadores }} & \multicolumn{3}{c|}{ Cenários } \\
\cline { 2 - 4 } & Pessimista & Conservador & Otimista \\
\hline Taxa interna de Retorno (\%) & - & - & - \\
\hline Rendimento Selic (\%) & $12,33 \%$ & $12,33 \%$ & $12,33 \%$ \\
\hline Valor Presente Líquido (R\$) & $-\mathrm{R} \$ 1.253 .567,51$ & $-\mathrm{R} \$ 1.095 .528,31$ & $-\mathrm{R} \$ 681.887,68$ \\
\hline
\end{tabular}

Fonte: dados da pesquisa (2009). 
Análise da viabilidade econômico-financeira da cafeicultura: um estudo nas principais regiões produtoras de café do Brasil Cássio Henrique Garcia Costa, Fabrício Teixeira Andrade, Luiz Gonzaga de Castro Júnior

Comprova-se que na maioria dos casos, o investimento em cafeicultura nas principais regiões brasileiras é menos rentável do que o emprego da capital em fundos atrelados à taxa Selic. Os resultados tornam-se ainda piores quando se consideram os investimentos com implantação das lavouras.

Deve ficar claro que o estudo não pretende inferir sobre situações pontuais de investimento no negócio cafeicultura. Tal análise depende do conhecimento do analista referente a cada processo produtivo, o que fará com que ele tenha a condição de determinar ou não a viabilidade dos projetos.

As variáveis empregadas no estudo são passíveis de alterações no curto prazo. Esta é uma limitação geral das análises de projetos. As constantes alterações de aspectos dos ambientes dos negócios fazem com que as análises de viabilidade sejam passíveis de questionamentos. Portanto, uma sugestão para trabalhos futuros é que cada vez mais sejam construídos cenários nas análises de projetos para cafeicultura.

\section{CONCLUSÃO}

O estudo permite concluir que investir em cafeicultura nas principais regiões produtoras do país é menos rentável na grande maioria dos casos quando comparada a taxa Selic. Por meio dos indicadores Taxa Interna de Retorno e Valor Presente Líquido é constatada a dificuldade das empresas rurais produtoras de café em conseguir rentabilidades satisfatórias. A situação se torna ainda menos favorável quando se consideram os gastos com a implantação das lavouras de café.

O presente estudo ressalta a importância de análises prévias para a aplicação do capital em alternativas diversas e não tem a pretensão de realizar inferências acerca da cafeicultura como um todo. O objetivo é difundir a importância de análises de viabilidade para cada situação, uma vez que, para cada empresa, as características de produtividade, custos e despesas sofrem grande variação, sendo fundamental uma análise individualizada. 
Análise da viabilidade econômico-financeira da cafeicultura: um estudo nas principais regiões produtoras de café do Brasil Cássio Henrique Garcia Costa, Fabrício Teixeira Andrade, Luiz Gonzaga de Castro Júnior

\section{REFERÊNCIAS}

ANDRADE, Maria Margarida de. (2002). Como preparar trabalhos de cursos de pósgraduação: noções práticas. (5 ed.). São Paulo: Atlas.

ASSOCIAÇÃO BRASILEIRA DA INDÚSTRIA DE CAFÉ. Indicadores da indústria de café no Brasil. Disponível em: <http://www.abic.com.br/>. Acesso em: 10/mar/2009.

BUARQUE, C. (1991). Avaliação econômica de projetos: uma apresentação didática. (8 ed.). Rio de Janeiro: Campus. 266 p.

CONTADOR, C. R. (1981). Avaliação social de projetos. São Paulo: Atlas. 316 p.

DE ZEN, S.; PERES, F.C. (2002). Painel agrícola como instrumento de comunicação. In: CONGRESSO BRASILEIRO DE ECONOMIA E SOCIOLOGIA RURAL, 40. Passo Fundo. Anais...Brasília: SOBER.

GIORDANO, S. (2003). Marketing e meio ambiente. In: NEVES, M.F.; CASTRO, L.T. Marketing e estratégia em agronegócios e desenvolvimento. São Paulo, Atlas. 369p.

GITMAN, L.J. (2004). Princípios de Administração Financeira. (10 ed.). São Paulo: Pearson Addison Wesley.

HARWOOD, J. et al. (1999). Managing risk in farming: concepts, research and analysis. Agricultural Economics Report, Minnesota, v. 774, p. 125.

LANNA, A. E. (2000). Economia dos Recursos Hídricos. Porto Alegre: Universidade Federal do Rio Grande do Sul. 301 p. (Apostila).

MARKOWITZ, H. Portfolio selection. The Journal of Finance, Jersey, v. 7.

MATIELLO, J.B.; SANTINATO, R.; GARCIA, A.W.R.; ALMEIDA, S.R.; FERNANDES, D.R. (2005). Cultura de café no Brasil: novo manual de recomendações. Rio de Janeiro: MAPA/PROCAFÉ. 438p.

NORONHA, J. F. (1987). Projetos agropecuários: administração financeira, orçamento e viabilidade econômica. (2 ed.). São Paulo: Atlas. 269 p.

REZENDE, J. L. P.; OLIVEIRA, A. D. (2001). Análise econômica e social de projetos florestais. Viçosa: Editora UFV. $389 \mathrm{p}$.

WEDEKIN, I.; CASTRO, P.R. de. (1999). Gestão do agribusiness na perspectiva 21. In: PINAZZA, L.A.; ALIMANDRO, R. (Org.). Reestruturação no agribusiness brasileiro: 
Análise da viabilidade econômico-financeira da cafeicultura: um estudo nas principais regiões produtoras de café do Brasil Cássio Henrique Garcia Costa, Fabrício Teixeira Andrade, Luiz Gonzaga de Castro Júnior

agronegócios no terceiro milênio. Rio de Janeiro: Associação Brasileira de Agribusiness. p.111-135.

WOILER, S.; MATHIAS, W. F. (1996). Projetos: planejamento, elaboração e análise. São Paulo: Atlas. 294 p.

Data de Submissão: 04/08/2010

Data de Aceite: 05/12/2011 